\title{
ZBTB16 Gene Variability Influences Obesity-Related Parameters and Serum Lipid Levels in Czech Adults
}

\author{
B. BENDLOVÁ ${ }^{1}$, M. VAŇKOVÁ ${ }^{1}$, M. HILL ${ }^{1}$, G. VACÍNOVÁ ${ }^{1}$, P. LUKÁŠOVÁ ${ }^{1}$, \\ D. VEJRAŽKOVÁ ${ }^{1}$, L. ŠEDOVÁ ${ }^{2}$, O. ŠEDA ${ }^{2}$, J. VČELÁK ${ }^{1}$ \\ ${ }^{1}$ Institute of Endocrinology, Prague, Czech Republic, ${ }^{2}$ Institute of Biology and Medical \\ Genetics, First Faculty of Medicine, Charles University and General University Hospital in Prague, \\ Prague, Czech Republic
}

Received July 3, 2017

Accepted July 13, 2017

\section{Summary}

The data derived from rat models and the preliminary results of human studies provide strong indices of involvement of common ZBTB16 variants in a range of cardiovascular and metabolic traits. This cross-sectional study in the Caucasian cohort of 1517 Czech adults aimed to verify the hypothesis that ZBTB16 gene variation directly affects obesity and serum lipid levels. Genotyping of nine polymorphisms of the ZBTB16 gene (rs11214863, rs593731, rs763857, rs2846027, rs681200, rs686989, rs661223, rs675044, rs567057) was performed. A multivariate bidirectional regression with the reduction of dimensionality (O2PLS model) revealed relationships between basal lipid levels and anthropometric parameters and some minor ZBTB16 alleles. In men, the predictors - age and presence of minor ZBTB16 alleles of rs686989, rs661223, rs675044, rs567057 - were associated with significantly higher body mass index, waist to hip ratio, body adiposity index, waist and abdominal circumferences, higher total cholesterol and LDL cholesterol and explained $20 \%$ of variability of these variables. In women, the predictors - age and presence of the rs686989 minor T allele were also associated with increased anthropometric parameters and total cholesterol and LDL cholesterol but the obtained O2PLS model explained only $7.8 \%$ of the variability of the explained variables. Our study confirmed that the selected gene variants of the transcription factor ZBTB16 influence the obesity-related parameters and lipid levels. This effect was more pronounced in men.

\section{Key words}

ZBTB16 • Multivariate regression $\bullet$ Body mass index $\bullet$ Body fat distribution $\bullet$ Lipids

\section{Corresponding author}

B. Bendlová, Department of Molecular Endocrinology, Institute of Endocrinology, Národní 8, Prague, 116 94, Czech Republic. E-mail: bbendlova@endo.cz

\section{Introduction}

The rapidly increasing incidence and prevalence of obesity and type 2 diabetes is becoming a major global health problem; however, the need for identification of relevant molecular targets and devising effective preventive and therapeutic algorithms is met by only a modest advancement of our knowledge. Metabolic syndrome is a group of risk factors (abdominal obesity, dyslipidemia, hypertension, elevated fasting glucose or impaired glucose tolerance) that can increase the susceptibility to develop diabetes, heart disease, and stroke (Alberti et al. 2009). All individual features of metabolic syndrome are complex traits with relatively balanced strength of heritable and environmental component. The heritability of individual components of metabolic syndrome ranges from 40 to $70 \%$. The manifestation of metabolic syndrome, its course and outcomes are driven by interacting forces of environment (including diet, physical activity and medication), individual genetic background and increasing age (Lusis et al. 2008, Seda et al. 2005a).

The identification of molecular mechanisms underlying complicated genome-environmental interactions is very difficult in humans due to the high complexity and heterogeneity. Nevertheless, many 
candidate genes which genetic variants increase the risk of the individual traits of metabolic syndrome have been identified. Particularly due to genome-wide association studies performed on very large cohorts, variants significantly associated with obesity, diabetes, dyslipidemia and hypertension have been revealed (http://www.gwascentral.org/, http://www.ebi.ac.uk/gwas). However, the biological function of many of them is still unknown and their contribution to the heritability of these pathophysiological features is small.

Thanks to animal model studies (Sedova et al. 2000, Seda et al. 2005b, Liska et al. 2009, Liska et al. 2014, Liska et al. 2016, Liska et al. 2017), the association between ZBTB16 and metabolic syndrome and its components was revealed. The aim of our study was to search for possible pathophysiological consequences of genetic variation in ZBTB16 gene in adult humans, especially with respect to obesity and lipid levels.

\section{Materials and Methods}

\section{Subjects}

A total of 1517 non-diabetic subjects (1281 women and 236 men) without hypolipidemic treatment participated in the study (their anthropometric and biochemical profile is shown in Table 1).

Participants were examined after signing an informed consent approved by the Ethics Committee of the Institute of Endocrinology. For the evaluation of basic biochemical parameters, $10 \mathrm{ml}$ of fasting blood was withdrawn in the morning. Blood samples were centrifuged and stored at $-80{ }^{\circ} \mathrm{C}$ until analyzed.

Table 1. Anthropometric and biochemical characteristics of the study subjects.

\begin{tabular}{lcc}
\hline & \multicolumn{1}{c}{ Median (95 \% confidence limits) } \\
\cline { 2 - 3 } Variable & Men (n=236) & Women (n=1281) \\
\hline Age (years) & $32.9(30.5,35.6)$ & $31.4(30.8,32.0)$ \\
\% normostenic, overweight, obesity & $52.8,38.7,8.5$ & $61,21.3,17.7$ \\
BMI $\left(\mathrm{kg} / \mathrm{m}^{2}\right)$ & $24.7(24.3,25.3)$ & $23.5(23.6,23.9)$ \\
WHR & $0.86(0.85,0.88)$ & $0.76(0.75,0.77)$ \\
WHtR & $0.48(0.46,0.49)$ & $0.45(0.44,0.46)$ \\
BAI & $23.3(22.6,23.6)$ & $28.0(27.6,28.3)$ \\
Abdomen circumference $(\mathrm{cm})$ & $88.5(87.3,90.4)$ & $84.5(83.5,85.5)$ \\
Hip circumference $(\mathrm{cm})$ & $99.5(98.2,100.5)$ & $100.0(99.4,100.5)$ \\
Waist circumference $(\mathrm{cm})$ & $85.9(83.5,87.6)$ & $75.5(74.7,76.4)$ \\
Total cholesterol $(\mathrm{mmol} / \mathrm{l})$ & $4.60(4.45,4.75)$ & $4.51(4.45,4.57)$ \\
HDL cholesterol $(\mathrm{mmol} / \mathrm{l})$ & $1.28(1.22,1.32)$ & $1.55(1.53,1.57)$ \\
LDL cholesterol $(\mathrm{mmol} / \mathrm{l})$ & $2.69(2.6,2.82)$ & $2.49(2.45,2.56)$ \\
Triacylglycerols $(\mathrm{mmol} / \mathrm{l})$ & $1.01(0.91,1.11)$ & $0.82(0.80,0.85)$ \\
\hline
\end{tabular}

\section{Anthropometric measurements}

Anthropometric data were obtained in the fasting state. Waist circumference was measured halfway between the rib cage and the pelvic bone. Hip and abdominal circumferences were measured at the maximal circumference of the hips, resp. abdomen. The waist to hip ratio (WHR) was calculated from these measurements. Waist-to-height ratio (WHtR) was defined as waist circumference divided by height, both measured in the same units. Body mass index (BMI) was calculated as the weight in kilograms divided by the square of the height in meters. Body adiposity index (BAI), a surrogate measure of body fat, was calculated as described elsewhere (Silva et al. 2017).

\section{Analytical methods}

Triacylglycerols, total cholesterol, and HDL cholesterol were assayed by enzymatic colorimetric test (Roche, Cobas 6000, Basel, Switzerland). LDL cholesterol was calculated as total cholesterol minus (triacylglycerols divided by 2.2) minus HDL cholesterol.

\section{Genetic analysis}

DNA was extracted from peripheral blood and 
stored at $-20{ }^{\circ} \mathrm{C}$ until analysis. Samples were genotyped by Endpoint Genotyping with TaqMan assays (Applied Biosystems, Foster City, CA, USA) using RealTime LC480 (Roche, Basel, Switzerland) and Biomark (Fluidigm, San Francisco, USA). Selection of the polymorphisms was based on the study Seda et al. (2008, unpublished data). For each of the nine polymorphism of ZBTB16 gene (rs11214863, rs593731, rs763857, rs2846027, rs681200, rs686989, rs661223, rs675044, rs567057) a special assay was designed. Distributions of genotypes did not significantly differ from HardyWeinberg equilibrium.

\section{Statistical analysis}

In this study, the use of multivariate bidirectional regression with the reduction of dimensionality (O2PLS) model (Trygg and Wold 2002) serves to assess relevant common characteristics explaining the relationships between lipid and anthropometric data on one side and minor alleles of polymorphisms in ZBTB16 gene on the other side. Using this approach, we also attempted to evaluate the importance of individual indices in the model and their statistical significance. The model consists of two mutually associated matrices $\mathrm{X}$ and $\mathrm{Y}$. These matrices are decomposed to so called predictive components explaining the relationships between $\mathrm{X}$ and $\mathrm{Y}$, two groups of orthogonal components explaining the relationships within $\mathrm{X}$ independently of $\mathrm{Y}$ and those within $\mathrm{Y}$ independently of $\mathrm{X}$ and to error terms including the unexplained variability in matrixes $\mathrm{X}$ and $\mathrm{Y}$, respectively. The orthogonal components and the error terms form an indispensable constitutive part of the model; however, they are not interesting for our purpose. The desired outcome of our O2PLS analysis is represented by the predictive components that are estimating relationship between ZBTB16 genotypes and biochemical or anthropometric phenotypes. Concerning our data, $\mathrm{X}$ matrix involves a carrier status of minor alleles of ZBTB16 polymorphisms and age, while the Y matrix involves the lipid and anthropometric parameters. The main outcomes of the O2PLS analysis is firstly the number of well interpretable, relevant and at the same time mutually independent general characteristics explaining the relationships between $\mathrm{X}$ and $\mathrm{Y}$, secondly the intensity and statistical significance of these relationships and finally, the importance and statistical significance of individual indices in $\mathrm{X}$ and $\mathrm{Y}$ for each of the aforementioned general characteristics (predictive components). Each continuous variable underwent checking for normality, homogeneity, symmetry and homoscedasticity (constant variance) before further processing. Most of these indices undergo a power transformation to meet the aforementioned assumptions. The data meeting these assumptions are normalized (the mean value is subtracted from each measurement and the result is divided by standard deviation) and the resulting dimensionless data formed from each continuous variables are analyzed by O2PLS together with binary genetic data. The measure of association between $\mathrm{X}$ and $\mathrm{Y}$ is firstly characterized by overall percent of variability shared between these matrices and secondly by a percent of variability in Y matrix explained by each predictive component. The importance of individual indices for individual predictive components is characterized by component loadings ranging from -1 (absolute negative correlation - linear dependence) to 1 (absolute positive correlation - linear dependence). The statistical certainty of component loadings is characterized by t-statistics, which are the ratios of component loadings to their standard errors and by levels of statistical significance calculated from the $\mathrm{t}$-statistics (correlation coefficient $\mathrm{R}$ ). The explained variability was tested by cross-validation. The crossvalidation is a method for assessing how much the statistical model is influenced by independent data. Statistical softwares Statgraphics Centurion, version XV from Statpoint Inc. (Herndon, Virginia, USA) for the power transformations and SIMCA-P v.12.0 from Umetrics AB (Umeå, Sweden) for O2PLS method were used.

\section{Results}

Table 2 demonstrates the ascertained frequencies of minor alleles and minor allele carriers of selected ZBTB16 polymorphisms in all study subjects. Tables 3 and 4 show the results of the corresponding O2PLS models for men and women, respectively. In men, several anthropometric parameters (waist and abdominal circumferences, BMI, WHR, WHtR and BAI) and lipids (total and LDL cholesterol) significantly positively correlate with carrier status of minor ZBTB16 alleles (rs567057, rs661223, rs675044 and rs686989). Table 4 demonstrates positive correlations of anthropometric parameters (waist and abdominal circumferences, BMI, WHR, WHtR and BAI) and lipids (total and LDL cholesterol) with carrier status of minor ZBTB16 
allele (rs686989) in women. The age was the main predictor of the studied parameters in men as well as in women. The O2PLS model explained $20 \%$ (18.5\% after cross-validation) of the total variability of predicted variables in men and only $7.8 \%(7.7 \%$ after crossvalidation) in women.

Table 2. Studied variants of $Z B T B 16$ gene and the frequency of minor alleles and minor allele carriers.

\begin{tabular}{lccc}
\hline $\begin{array}{l}\text { SNPs of } \\
\text { ZBTB16 } \\
\text { gene }\end{array}$ & $\begin{array}{c}\text { Minor } \\
\text { alelle }\end{array}$ & $\begin{array}{c}\text { Minor alelle } \\
\text { frequency } \\
\text { (\%) }\end{array}$ & $\begin{array}{c}\text { Minor alelle } \\
\text { carriers } \\
\text { (\%) }\end{array}$ \\
\hline rs11214863 & T & 31.4 & 52.5 \\
rs593731 & G & 16.8 & 30.7 \\
rs763857 & T & 37.1 & 60.8 \\
rs2846027 & T & 30.2 & 52.4 \\
rs681200 & C & 20.1 & 36.0 \\
rs686989 & $\mathrm{A}$ & 11.5 & 21.4 \\
rs661223 & $\mathrm{T}$ & 7.1 & 13.7 \\
rs675044 & $\mathrm{G}$ & 14.5 & 26.8 \\
rs567057 & $\mathrm{G}$ & 7.2 & 13.9 \\
\hline
\end{tabular}

\section{Discussion}

There is growing evidence that ZBTB16 (also known as PLZF) protein is an important pleiotropic factor influencing cell cycle and many signaling pathways via interactions with nuclear receptors and via induction of epigenetic changes. Several studies using the experimental animal models and human tissue cultures demonstrated the evidence of the role of ZBTB16 in adipogenesis, lipid metabolism, cardiovascular traits and carbohydrate metabolism/insulin sensitivity. So, the altered ZBTB16 function could be one of the genetic triggers in the development of metabolic syndrome. The review summarizing the current knowledge on ZBTB16 as a possible node of metabolic syndrome is given in this issue by Seda et al. (2017).

Our study shows for the first time that ZBTB16 gene variants also correlate with anthropometric parameters and lipid levels in human cohort. The minor allele carrier status of four ZBTB16 variants in intron 3 (rs686989, rs661223, rs675044, rs567057) significantly positively correlated with obesity related traits and total and LDL cholesterol. It could be supposed that these minor intronic variants are in linkage disequilibrium with still unknown causal variant or directly decrease ZBTB16 expression and/or deteriorate its function. In the animal model, a $3 \mathrm{~kb}$ deletion in intron 2 of Zbtb16 gene was shown to affect a range of metabolic and developmental traits (Liska et al. 2009, Liska et al. 2014).

Our findings are in concordance with recent studies confirming that expression of Zbtb16/ZBTB16 plays an important role in the adipogenesis in white adipose tissue (Mikkelsen et al. 2010, Ambele et al. 2016), as well as in brown adipose tissue (Plasier et al. 2012). Using genome-wide data, Mikkelsen et al. (2010) discovered ZBTB16 as a new factor with anti-adipogenic activity. Overexpression of Zbtb16 suppressed the adipogenesis in L1 cells. Conversely, the RNAi-mediated knockdown of Zbtb16 enhanced the adipogenesis in L1 cells. Zbtb16 overexpression in brown adipocytes led to the induction of thermogenesis, accompanied by increased fatty acid oxidation, glycolysis and increased number and activity of mitochondria. It was accompanied by decreased triacylglycerols content and increased carbohydrate utilization in brown adipocytes. Moreover, using Hybrid Mouse Diversity Panel, Zbtb16 mRNA levels were inversely correlated with overall body weight and body fat content in four major white adipose tissue depots (Plasier et al. 2012). These authors also reported that in visceral adipose tissue of obese diabetic women, ZBTB16 expression was significantly lower than in age- and BMI-matched normal glucose tolerant controls (Plasier et al. 2012). Downregulation of Zbtb16 in Dgat1transgenic mice favoring intramuscular fat deposition was recently reported by Ying et al. (2017).

On the other hand, transcriptome analysis of adipogenesis in human adipose-derived stromal cells revealed that ZBTB16 transcription factor was up-regulated throughout the whole differentiation process into adipocytes (Ambele et al. 2016).

As for the lipid metabolism, the SHR-Plzf $f^{+/}$ targeted model (Liska et al. 2017) as well as SHR-Lx congenic strain (with intronic 3kb-deletion in Zbtb16; Seda et al. 2005b) exhibit effect of Zbtb16 disruption on lipid levels. SHR-Plzf $f^{+/}$rats had lower levels of triacylglycerols and cholesterol, whereas SHR-Lx congenic rats were prone to glucocorticoid-induced dyslipidemia compared to SHR controls (Seda et al. 2005b). In an experiment with fatty acid treatments, Zbtb16 was one of the most upregulated genes in the heart tissue, but surprisingly, this upregulation was independent of PPAR alpha (Georgiadi et al. 2012). 
Table 3. Relationships between basal lipids and anthropometric parameters, and minor ZBTB16 allele carriers as evaluated by O2PLS model in men.

\begin{tabular}{|c|c|c|c|c|c|}
\hline & \multirow[b]{2}{*}{ Variable } & \multicolumn{4}{|c|}{ Predictive component } \\
\hline & & Component loading ${ }^{a}$ & t-statistics ${ }^{b}$ & $\mathbf{R}^{\mathbf{c}}$ & \\
\hline Relevant predictors & rs567057 (AG+GG) & 0.182 & 3.08 & 0.177 & $* *$ \\
\hline \multirow[t]{8}{*}{$($ matrix $\boldsymbol{X})$} & rs661223 (CT+TT) & 0.151 & 2.56 & 0.144 & $*$ \\
\hline & rs675044 (AG+GG) & 0.181 & 3.06 & 0.184 & $* *$ \\
\hline & rs686989 (AG+GG) & 0.165 & 2.39 & 0.164 & $*$ \\
\hline & Age & 0.941 & 24.29 & 0.999 & $* *$ \\
\hline & Abdomen & 0.336 & 2.85 & 0.470 & $*$ \\
\hline & Waist & 0.354 & 2.97 & 0.507 & $*$ \\
\hline & BMI & 0.285 & 2.49 & 0.358 & $*$ \\
\hline & WHR & 0.387 & 3.35 & 0.616 & $* *$ \\
\hline \multirow[t]{5}{*}{ (matrix $\boldsymbol{Y})$} & WHtR & 0.365 & 3.24 & 0.570 & ** \\
\hline & BAI & 0.257 & 2.62 & 0.404 & $*$ \\
\hline & Total cholesterol & 0.396 & 2.28 & 0.420 & $*$ \\
\hline & Triacylglycerols & 0.168 & 0.63 & 0.144 & \\
\hline & LDL cholesterol & 0.407 & 2.24 & 0.391 & $*$ \\
\hline Explained variabilit & & \multicolumn{4}{|c|}{$20 \%$ (18.5\% after cross-validation) } \\
\hline
\end{tabular}

$\mathrm{a}$ - component loadings for the predictive components expressed as regression coefficients, $\mathrm{b}-\mathrm{t}$-statistic is the ratio of the regression coefficient to its standard error, $\mathrm{c}-$ components loadings expressed as a correlation coefficients with predictive component, $* \mathrm{p}<0.05$, $* * \mathrm{p}<0.01$.

Table 4. Relationships between basal lipids and anthropometric parameters, and minor ZBTB16 allele carriers as evaluated by O2PLS model in women.

\begin{tabular}{llcccc}
\hline & & \multicolumn{4}{c}{ Predictive component } \\
\cline { 3 - 6 } & Variable & Component loading $^{\mathbf{a}}$ & t-statistics $^{\mathbf{b}}$ & $\mathbf{R}^{\mathbf{c}}$ & \\
\hline Relevant predictors & rs686989 (AG+GG) & 0.117 & 1.99 & 0.117 & $*$ \\
& Age & 0.993 & 155.15 & 0.995 & $* *$ \\
\hline & Abdomen & 0.325 & 3.63 & 0.327 & $* *$ \\
& Hip & 0.157 & 1.68 & 0.129 & \\
(matrix $\boldsymbol{Y}$ ) & Waist & 0.335 & 3.50 & 0.314 & $* *$ \\
& BMI & 0.235 & 2.36 & 0.201 & $*$ \\
& WHR & 0.385 & 5.07 & 0.376 & $* *$ \\
& WHtR & 0.341 & 3.69 & 0.340 & $* *$ \\
& BAI & 0.182 & 2.28 & 0.200 & $*$ \\
& Total cholesterol & 0.340 & 3.15 & 0.283 & $* *$ \\
& LDL cholesterol & 0.374 & 3.61 & 0.296 & $* *$ \\
\hline
\end{tabular}

\section{Explained variability}

$7.8 \%$ (7.7 \% after cross-validation)

$\mathrm{a}$ - component loadings for the predictive components expressed as regression coefficients, $\mathrm{b}-\mathrm{t}$-statistic is the ratio of the regression coefficient to its standard error, $\mathrm{c}-$ components loadings expressed as a correlation coefficients with predictive component, $* \mathrm{p}<0.05$, $* * p<0.01$.

The exact biological role of ZBTB16 in the adipogenesis and lipid metabolism is complex and remains to be elucidated. However, there are many possible relations between entities (genes, chemicals) 
connecting ZBTB16 to symptoms of metabolic syndrome. The potential functional network links involving the ZBTB16 node are described in a review of Seda et al. (2017). Due to the key role of ZBTB16 in crucial biological processes, its expression is tightly regulated by alternative splicing, several posttranscriptional modifications (reviewed by Seda et al. 2017), as well as by hormones such as glucocorticoids (Fahnenstich et al. 2003, Chen et al. 2014), progesterone and estradiol (Dassen et al. 2007, Cheng et al. 2007) and nutrients - fatty acids (Georgiadi et al. 2012, de Wilde et al. 2008). These hormonal influences could explain our different results for men and women, as the effect of carrying ZBTB16 minor alleles was more pronounced in men.

Our data support the possible role of the ZBTB16 variability in the pathogenesis of obesity and impaired lipid metabolism in humans. In view of the fact that this gene has not been discovered by relevant GWAS (due to insufficient statistical significance), it may appear that the contribution of $Z B T B 16$ gene variability on phenotypical features is rather small but its effect is probably modified by other factors or dependent on a particular genetic or biochemical/metabolic context. To fully evaluate the effect of ZBTB16 variation on body adiposity and body fat distribution, lipid levels and related traits, it might be necessary to utilize analytical models incorporating broader interactions (gene-gene, gene-nutrient, genehormone etc.).

\section{Conflict of Interest}

There is no conflict of interest.

\section{Acknowledgements}

This study was supported by the Grants GACR 15-04871S from the Czech Science Foundation and MH CZ - DRO (Institute of Endocrinology - EU, 00023761) and by the MEYS CR (OP RDE, Excellent Research ENDO.CZ).

\section{Abbreviations}

BAI - Body Adiposity Index, BMI - Body Mass Index, GWAS - Genome-Wide Association Study, HDL - High Density Lipoprotein, LDL - Low Density Lipoprotein, O2PLS - Bidirectional Orthogonal Projections to Latent Structure, PLZF - Promyelocytic Leukemia Zinc Finger, WHR - Waist to Hip Ratio, WHtR - Waist to Height Ratio, ZBTB16 - Zinc Finger and BTB Domain Containing 16.

\section{References}

ALBERTI KG, ECKEL RH, GRUNDY SM, ZIMMET PZ, CLEEMAN JI, DONATO KA, FRUCHART JC, JAMES WP, LORIA CM, SMITH SC JR, INTERNATIONAL DIABETES FEDERATION TASK FORCE ON EPIDEMIOLOGY AND PREVENTION; NATIONAL HEART LUNG, AND BLOOD INSTITUTE; AMERICAN HEART ASSOCIATION; WORLD HEART FEDERATION; INTERNATIONAL ATHEROSCLEROSIS SOCIETY; INTERNATIONAL ASSOCIATION FOR THE STUDY OF OBESITY: Harmonizing the metabolic syndrome: a joint interim statement of the International Diabetes Federation Task Force on Epidemiology and Prevention; National Heart, Lung, and Blood Institute; American Heart Association; World Heart Federation; International Atherosclerosis Society; and International Association for the Study of Obesity. Circulation 120: 1640-1645, 2009.

AMBELE MA, DESSELS C, DURANDT C, PEPPER MS: Genome-wide analysis of gene expression during adipogenesis in human adipose-derived stromal cells reveals novel patterns of gene expression during adipocyte differentiation. Stem Cell Res 16: 725-734, 2016.

CHEN S, QIAN J, SHI X, GAO T, LIANG T, LIU C: Control of hepatic gluconeogenesis by the promyelocytic leukemia zinc finger protein. Mol Endocrinol 28: 1987-1998, 2014.

CHENG CW, BIELBY H, LICENCE D, SMITH SK, PRINT CG, CHARNOCK-JONES DS: Quantitative cellular and molecular analysis of the effect of progesterone withdrawal in a murine model of decidualization. Biol Reprod 76: 871-883, 2007.

DASSEN H, PUNYADEERA C, KAMPS R, KLOMP J, DUNSELMAN G, DIJCKS F, DE GOEIJ A, EDERVEEN A, GROOTHUIS P: Progesterone regulation of implantation-related genes: new insights into the role of oestrogen. Cell Mol Life Sci 64: 1009-1032, 2007. 
De WILDE J, MOHREN R, VAN DEN BERG S, BOEKSCHOTEN M, DIJK KW, De GROOT P, MÜLLER M, MARIMAN E, SMIT E: Short-term high fat-feeding results in morphological and metabolic adaptations in the skeletal muscle of C57BL/6J mice. Physiol Genomic 32: 360-369, 2008.

FAHNENSTICH J, NANDY A, MILDE-LANGOSCH K, SCHNEIDER-MERCK T, WALTHER N, GELLERSEN B: Promyelocytic leukaemia zinc finger protein (PLZF) is a glucocorticoid- and progesterone-induced transcription factor in human endometrial stromal cells and myometrial smooth muscle cells. Mol Hum Reprod 9: 611-623, 2003.

GEORGIADI A, BOEKSCHOTEN MV, MULLER M, KERSTEN S: Detailed transcriptomics analysis of the effect of dietary fatty acids on gene expression in the heart. Physiol Genomics 44: 352-361, 2012.

LISKA F, SNAJDR P, SEDOVA L, SEDA O, CHYLIKOVA B, SLAMOVA P, KREJCI E, SEDMERA D, GRIM M, KRENOVA D, KREN V: Deletion of a conserved noncoding sequence in Plzf intron leads to Plzf downregulation in limb bud and polydactyly in the rat. Dev Dyn 238: 673-684, 2009.

LISKA F, MANCINI M, KRUPKOVA M, CHYLIKOVA B, KRENOVA D, SEDA O, SILHAVY J, MLEJNEK P, LANDA V, ZIDEK V, D'AMATI G, PRAVENEC M, KREN V: Plzf as a candidate gene predisposing the spontaneously hypertensive rat to hypertension, left ventricular hypertrophy, and interstitial fibrosis. $A m J$ Hypertens 27: 99-106, 2014.

LISKA F, PETERKOVA R, PETERKA M, LANDA V, ZIDEK V, MLEJNEK P, SILHAVY J, SIMAKOVA M, KREN V, STARKE CG, VOYTAS D F, IZSVAK Z, PRAVENEC M: Targeting of the Plzf gene in the rat by transcription activator-like effector nuclease results in caudal regression syndrome in spontaneously hypertensive rats. PLoS One 11: e0164206, 2016.

LISKA F, LANDA V, ZIDEK V, MLEJNEK P, SILHAVY J, SIMAKOVA M, STRNAD H, TRNOVSKA J, SKOP V, KAZDOVA L, STARKER C, VOYTAS D, ISZVAK Z, MANCINI M, SEDA O, KREN V, PRAVENEC M: Downregulation of Plzf gene ameliorates metabolic and cardiac traits in the spontaneously hypertensive rat. Hypertension 69: 1084-1091, 2017.

LUSIS AJ, ATTIE AD, REUE K: Metabolic syndrome: from epidemiology to systems biology. Nat Rev Genet 9: 819-830, 2008.

MIKKELSEN TS, XU Z, ZHANG X, WANG L, GIMBLE JM, LANDER ES, ROSEN ED: Comparative epigenomic analysis of murine and human adipogenesis. Cell 143: 156-169, 2010.

PLAISIER CL, BENNETT BJ, HE A, GUAN B, LUSIS AJ, REUE K, VERGNES L: Zbtb16 has a role in brown adipocyte bioenergetics. Nutr Diabetes 2: e46, 2012.

SEDA O, LISKA F, KRENOVA D, KAZDOVA L, SEDOVA L, ZIMA T, PENG J, PELINKOVA K, TREMBLAY J, HAMET P, KREN V: Dynamic genetic architecture of metabolic syndrome attributes in the rat. Physiol Genomics 21: 243-252, 2005a.

SEDA O, LISKA F, SEDOVA L, KAZDOVA L, KRENOVA D, KREN V: A 14-gene region of rat chromosome 8 in SHR-derived polydactylous congenic substrain affects muscle-specific insulin resistance, dyslipidaemia and visceral adiposity. Folia Biol (Praha) 51: 53-61, 2005 b.

SEDA O, TREMBLAY J, GAUDET D, BRUNELLE PL, GURAU A, MERLO E, PILOTE L, ORLOV SN, BOULVA F, PETROVICH M, KOTCHEN TA, COWLEY AW JR, HAMET P: Systematic, genome-wide, sex-specific linkage of cardiovascular traits in French Canadians. Hypertension 51: 1156-1162, 2008.

SEDA O, SEDOVA L, VCELAK J, VANKOVA M, LISKA F, BENDLOVA B: ZBTB16 and metabolic syndrome: a network perspective. Physiol Res (Suppl 3) 66: S357-S365, 2017.

SEDOVA L, KAZDOVA L, SEDA O, KRENOVA D, KREN V: Rat inbred PD/cub strain as a model of dyslipidemia and insulin resistance. Folia Biol (Praha) 46: 99-106, 2000.

SILVA BR, MIALICH MS, HOFFMAN DJ, JORDÃO AA: BMI, BMIfat, BAI or BAIFels - Which is the best adiposity index for the detection of excess weight? Nutr Hosp 34: 389-395, 2017.

TRYGG J, WOLD S: Orthogonal projections to latent structure. J Chemometrics 16: 119-128, 2002.

YING F, GU H, XIONG Y, ZUO B: Analysis of differentially expressed genes in gastrocnemius muscle between DGAT1 transgenic mice and wild-type mice. Biomed Res Int 2017: 5404682, 2017. 